\title{
The burden of illness and economic evaluation for COPD
}

\author{
S.D. Ramsey*, S.D. Sullivan\#
}

The burden of illness and economic evaluation for COPD. S.D. Ramsey, S.D. Sullivan. (C) ERS Journals Ltd 2003.

ABSTRACT: In today's cost-conscious environment, understanding the economic implications associated with disease processes and their treatments is as important as understanding their clinical impact.

Medical expenditures for treating chronic obstructive pulmonary disease (COPD) and the indirect costs of morbidity can represent a substantial economic and social burden. Very little economic information concerning COPD is available, however, particularly outside of a few very well-developed Western nations.

This article will provide an approach for conducting high-quality studies aimed at estimating the economic burden of chronic obstructive pulmonary disease and for making economic evaluations of healthcare interventions aimed at preventing and treating this disease.

Eur Respir J 2003; 21: Suppl. 41, 29s-35s.
*Fred Hutchinson Cancer Research Center and the Dept of Pharmacy, and ${ }^{\#}$ the Dept of Medicine, University of Washington, Seattle, WA, USA.

Correspondence: S.D. Ramsey, Fred Hutchinson Cancer Research Center, 1100 Fairview Avenue North (MP-900), PO Box 19024, Seattle, WA 98109, USA.

Fax: 12066677850

E-mail: sramsey@fhcrc.org

Keywords: Direct medical costs, direct nonmedical costs, economic evaluations, friction costs, human capital, productivity costs

Received: August 212002

Accepted after revision: February 202003
Emphysema affects $\sim 1.9$ million Americans and is one of the fastest growing causes of morbidity and mortality in the USA $[1,2]$. Worldwide, the social burden of chronic obstructive pulmonary disease (COPD), in terms of days lost to disability, is expected to increase from twelfth to fifth among all chronic diseases from 1990-2020 [3]. Given the prevalence of this disease and the duration of illness for those affected, medical expenditures for treating COPD and the indirect costs of morbidity can represent a substantial economic and social burden for societies and for public and private payers. More importantly, because emphysema is highly prevalent, new treatments that are widely adopted for this condition, even if inexpensive at the individual patient level, can have a tremendous impact on the overall economic burden of the disease.

In today's cost-conscious environment, evaluating the economic impact of new therapies has become nearly as important as understanding their clinical impact. As healthcare costs continue to escalate, more emphasis is being placed on understanding the economic implications associated with disease processes and their treatments. Unfortunately, very little economic information concerning COPD is available, particularly outside of a few developed Western nations.

Given the rising prevalence of COPD worldwide, it is urgently necessary to understand its economic burden and to provide more robust evaluations of healthcare interventions designed to reduce its incidence and impact. Studies designed for making decisions and policy must apply robust methods and report results in a standardised fashion.

This article will provide an approach for conducting quality studies aimed at estimating the economic burden of COPD and cost-effectiveness analyses (CEAs) of healthcare interventions for prevention and treatment. After defining terms, the article discusses important issues that must be considered for any study measuring the costs of a disease or treatment. Subsequent sections discuss methods for conducting CEAs, use of administrative databases for estimating medical costs methods for distinguishing COPD-related versus non-COPDrelated healthcare use and other relevant analysis issues. The final section argues for the creation of a general healthcare policy model for COPD.

\section{Distinguishing burden-of-illness studies from cost-effectiveness analyses}

It is important to distinguish between burden-of-illness studies and CEAs of new interventions for COPD. Burden-ofillness studies, also called cost-of-illness studies, are designed to estimate the economic impact of a particular disease on a particular society (usually a nation) in monetary terms. The usual purpose of these studies is to highlight the cost that a particular "underappreciated" disease is extracting from society. Although this kind of information is of limited value to policy-makers, COPD burden-of-illness studies can highlight the variation in burden of illness globally, allowing intercountry comparisons.

CEAs refer to studies designed to evaluate the incremental impact of a particular COPD therapy or programme (usually new) versus the conventional approach. In recent years, standardised methods for conducting and reporting these studies have been embraced [4-8]. This article will not provide a comprehensive review of these methods but will focus on the aspects of economic studies that are of particular relevance to the COPD population.

\section{Capturing relevant costs related to chronic obstructive pulmonary disease and its treatment}

Economic studies of COPD must include all relevant costs associated with the illness. Such costs should include not only 
the intervention of interest (e.g. inhaled bronchodilator therapy) but also all components associated with therapy, such as nebuliser equipment. Such costs can be divided into programme, direct medical, direct nonmedical and productivity costs.

Programme costs refer to costs associated with building the infrastructure needed to deliver the technology. Many studies fail to take into account programme costs when evaluating interventions. For example, an evaluation of a new, intensive, smoking-cessation clinic should include clinic costs (such as rent for office space and staff costs) amortised across the patient group as well as the cost of associated therapies, such as nicotine patches or buspirone. Direct medical costs include all medical goods and services used to treat the illness. Usually, these costs are the easiest ones to identify and are thus part of most economic studies.

Direct nonmedical costs include items related to care not directly linked to the healthcare system. Comprehensive evaluations of nonmedical costs are needed for COPD. Such costs can include hired caregiver expenses, costs to the family, lost wages of family caregivers, expenses associated with modifications to living facilities and transportation and parking costs for patients visiting their physicians. These costs are not usually reimbursed by health insurance and are difficult to track, thus, they are often excluded from economic studies. As a result, almost no information exists on the value of direct nonmedical costs in COPD. This may be an important oversight, particularly for developing countries. For example, transportation costs may be one of the largest expenses for those who have to travel from remote areas to receive care.

Productivity costs refer to the value of lost wages resulting from illness and from seeking treatment. They are particularly difficult to estimate and are usually excluded from economic evaluations. Productivity is reduced by sporadic absences, visits to healthcare providers and premature mortality. Even more than direct nonmedical costs, this may be a particularly important omission where COPD is concerned, especially for burden-of-illness studies in developing countries. Highly developed countries will spend a larger share of their resources on medical care for COPD, whereas the burden of illness for developing countries is proportionally greater for productivity loss caused by the impact of the disease. Productivity costs, therefore, should be given particular attention in future studies concerning the impact of COPD on developing countries. The value of permanent work loss is particularly important for diseases with high rates of premature mortality, such as COPD. Owing to the potential importance of productivity in COPD, the two major approaches to valuing productivity (human capital and friction cost) are reviewed here in some detail.

\section{Human capital and friction cost approaches to valuing productivity costs}

The traditional approach to evaluating the impact of productivity loss caused by illness is the human capital approach. This term derives from the observation that a person's earnings over a lifetime reflect an investment in that individual through education, on-the-job training and work experience $[9,10]$. These investments influence the individual's value to the economy, and thus productivity loss is usually valued using market wage rates. For those not working for a wage (e.g. homemakers), wages are valued at those that replacement workers would earn for their specific services.

The friction cost method differs from the human capital approach in that it allows for the replacement of an absent worker by other workers or by those in the unemployed pool. The friction cost method values productivity as the loss incurred during the time between a person's absence from work or termination of employment and the time at which another worker fills that position [11-13]. The time required for worker replacement is called the "friction period". A stated advantage of the friction cost method is that, unlike the human capital method, it takes into account the fact that employees with long-term illness or disabilities can be replaced in markets with less than full employment. As a result, the friction cost method tends to provide lower estimates of productivity loss due to illness than the human capital method.

Unfortunately for researchers, there is no general agreement on whether the human capital or friction cost method is more valid for measuring the productivity costs of illness [14-17]. Further complicating the matter is that the estimate will vary greatly depending on which method is applied. For example, in a study of schizophrenia's impact on productivity, the human capital and friction cost methods resulted in an 85-fold difference in the estimate of productivity costs [18].

\section{Time horizon}

All downstream effects related to treatment for COPD should be included in cost studies. These costs should be tracked or modelled during the time that the intervention is expected to affect the individual or group. Often in the case of COPD, this time horizon equals a person's lifetime. Figure 1 shows a list of relevant costs for a study of lung reduction surgery for emphysema [19].

\section{Key factors influencing cost}

The call to "capture all costs" must be tempered by the reality of the study design's limitations and the budget available for conducting economic analyses. Since there is no comparison group in burden-of-illness evaluations, comprehensiveness is more important for these studies than for CEAs of

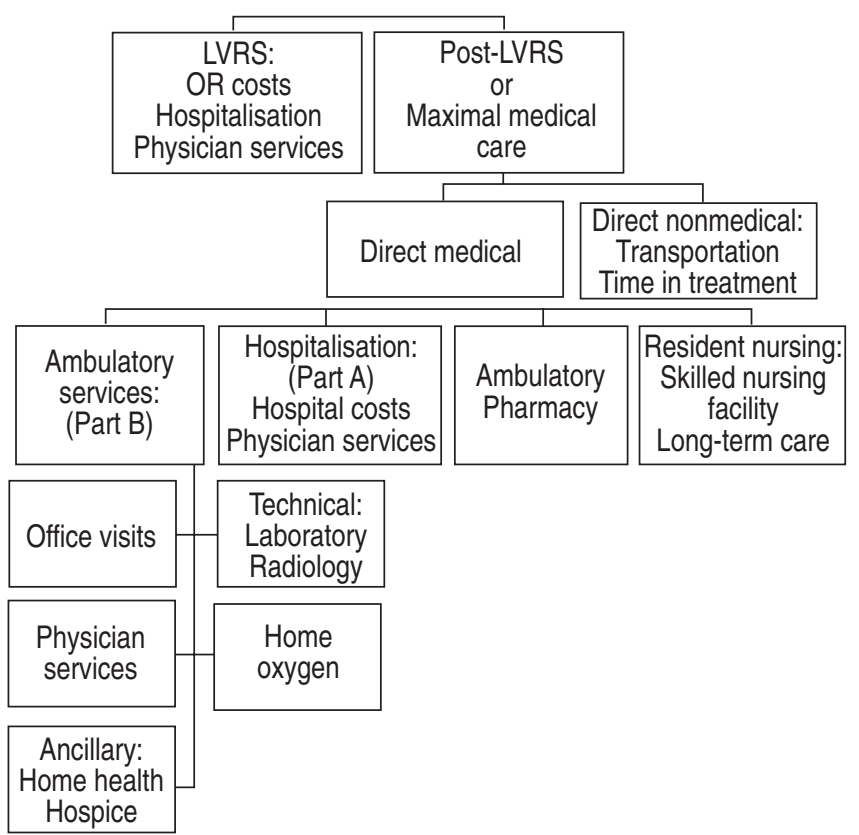

Fig. 1.- Cost elements for a study of lung volume reduction surgery (LVRS) versus standard care for persons with severe chronic obstructive pulmonary disease. The time horizon for the cost analysis is the lifetime of the patient from the time of randomisation. Adapted from data from [19]. 
healthcare programmes. For CEAs, the intervention of interest is likely to have a large effect on some aspects of healthcare utilisation (e.g. hospital days), but little on other aspects. CEAs are an incremental form of analysis and thus it is only necessary to measure healthcare items that are expected to vary between the intervention and control groups. Of course, it is difficult to predict beforehand what will vary as a result of the intervention. Studies have shown that the primary "costdriver" for COPD is hospital care for exacerbations, accounting for nearly $70 \%$ of all direct medical costs in developed countries for this disease [20-25]. Thus, if the intervention is expected to influence hospital care significantly, this may be the only item necessary to measure accurately. Other items with more subtle effects (e.g. office visits, medications) will probably require a more comprehensive analysis.

\section{Methodological issues for cost-effectiveness studies}

Cost-effectiveness studies are now common in medicine and have been applied to several therapies for COPD. Nevertheless, outside of smoking-cessation programmes [26-32], few high-quality CEAs exist for widely used COPD therapies [33]. In fairness to researchers, few therapeutic breakthroughs for this disease have occurred and many traditional therapies are perceived as only modestly effective (it could be argued that minimally effective therapies are not cost-effective and should not be applied). More recently, however, several therapies have begun development for persons with COPD [34, 35] (table 1). Ever tightening health budgets will force payers to scrutinise the value for expenditures of these new therapies more closely. In this context, it is an opportune time to review the important issues involved for conducting robust CEA evaluations of treatments. Researchers have developed guidelines for conducting CEAs of healthcare interventions [4, 5]. Items of particular interest to COPD evaluations are reviewed here.

Table 1.-New therapies under development for chronic obstructive pulmonary disease

\begin{tabular}{|c|c|}
\hline Bronchodilators & $\begin{array}{l}\text { Tiotropium bromide } \\
\text { Selective phosphodiesterase type-IV } \\
\text { inhibitors }\end{array}$ \\
\hline Mediator antagonists & $\begin{array}{l}\text { Leukotriene } \mathrm{B}_{4} \text { antagonists } \\
\text { Lipoxygenase inhibitors } \\
\text { Chemokine inhibitors } \\
\text { Tumour necrosis factor inhibitors }\end{array}$ \\
\hline $\begin{array}{l}\text { Anti-inflammatory } \\
\text { drugs }\end{array}$ & $\begin{array}{l}\text { Phosphodiesterase inhibitors } \\
\text { Transcription factor nuclear factor- } \kappa \mathrm{B} \\
\text { inhibitors } \\
\text { Adhesion molecule blockers }\end{array}$ \\
\hline Proteinase inhibitors & $\begin{array}{l}\text { Neutrophil elastase inhibitors } \\
\text { Cathepsin G and proteinase- } 3 \text { inhibitors } \\
\text { Matrix metalloproteinase inhibitors } \\
\text { Serine proteinase inhibitors (serpins) }\end{array}$ \\
\hline Mucoregulators & $\begin{array}{l}\text { Tachykinin antagonists } \\
\text { Sensory neuropeptide inhibitors } \\
\text { Mediator and enzyme inhibitors } \\
\text { Mucin gene suppressors } \\
\text { Mucolytic agents } \\
\text { Macrolide antibiotics } \\
\text { Purinoceptor blockers }\end{array}$ \\
\hline Alveolar repair & $\begin{array}{l}\text { Retinoic acid-receptor subtype agonists } \\
\text { Hepatocyte growth factor }\end{array}$ \\
\hline Surgery & Lung volume reduction surgery \\
\hline
\end{tabular}

Adapted from data from [19].

\section{Perspective}

The economic impact of COPD varies widely from country to country, and health-insurance coverage for COPD services, even in countries with nationalised health-insurance systems, can vary significantly. Thus, because of these issues, it is important for researchers to state clearly the perspective for their analysis. Options can include perspectives from society, health-insurer, hospital or patient. Although the health-insurer's perspective is the most commonly employed for CEAs, in many cases it may not be adequate, and for several reasons. First, this perspective ignores productivity costs, which may be a substantial part of COPD's economic picture. Second, out-of-pocket costs for therapies can be substantial even in developed countries. Third, in developing countries, nonmedical costs, such as transportation, may be the greatest barrier to obtaining care. Consequently, the societal perspective should be taken for all studies. Other perspectives are encouraged and may be particularly relevant to the situation at hand (e.g. smoking cessation in rural Africa). In particular, the healthinsurer's perspective is important because it will best reflect the perspective of the decision-makers of private and governmental health-funding agencies.

\section{Identifying persons with chronic obstructive pulmonary disease}

Many economic studies use administrative databases to examine the impact of therapies for COPD retrospectively. COPD is an insidious condition that can progress undetected for years or can mimic other conditions, and thus it is important to ensure that those identified administratively actually have the disease. The International Classification of Diseases codes are notoriously inaccurate for identifying those with many conditions, including COPD [36]. For this reason, additional measures must be taken to ensure the validity of the sample. These measures can include chart audits of identified cases, selecting patients from disease or clinical trial registries or selection using clinical parameters first (e.g. spirometry). Regardless of the method, the approach for case ascertainment must be described clearly.

The method of case ascertainment should also indicate the severity of cohort illness. Severity can be defined using clinical parameters (e.g. forced expiratory volume in one second (FEV1)) or health resource use criteria (e.g. number of COPD hospitalisations in the past year). As no consensus exists regarding severity levels in COPD, either by clinical or healthservice definitions, it is unavoidable that any definition of severity will be subjective. Nevertheless, defining severity clearly will facilitate comparisons among other studies. Describing case ascertainment and severity is particularly important for burden-of-illness studies because these are usually derived from administrative data. CEAs linked with clinical studies having careful case identification are ideal, although they may pose problems for the external validity of findings.

\section{Time horizon}

COPD is a lifelong illness, but it is not feasible to monitor health costs or outcomes for COPD patients over years or a lifetime. Ideally, costs and outcomes should be tracked for a minimum of 12 months to capture a sufficient number of important end-points, such as exacerbations requiring hospital or emergency department visits, and account for seasonal variation. To capture the time horizon necessary for CEAs, studies should either follow or model the impact of COPD 
over a lifetime. Segmenting the history into time windows that are particularly relevant to the analytic perspective is acceptable as a subanalysis.

\section{Credible alternatives to the intervention of interest}

New interventions must be compared with the standard of care for persons who have COPD and other mitigating factors, such as age, sex and comorbidities. For this reason, economic evaluations based on placebo-controlled studies are usually inappropriate. Economic evaluations of new drugs should not be based on efficacy trials, unless the trials include the full complement of usual therapy in the absence of the new treatment, for example.

\section{Discounting}

Since the time horizon for therapy in COPD is long, costs and effects accruing in future years should be discounted to their present value using widely accepted rates, as well as rates that are established for the healthcare-financing agencies of the country of origin [37].

\section{Administrative databases for estimating direct medical costs}

Administrative databases are convenient and have the advantage of following patients for extended periods of time. As noted previously, however, it is first necessary to be sure that those identified administratively as having COPD indeed have the condition. A few other important issues should be considered when using administrative databases for CEA evaluations. First, some do not capture all direct medical-care costs related to the disease. For example, the US Medicare programme does not pay for outpatient prescription drugs. In addition, it is important to know the enrolment status of those followed. In the USA, patients can unenrol from health plans when they switch jobs, retire or if their employer chooses a new health plan. This issue is also important for cost-analysis methods.

\section{Methodological issues for estimating costs of care: disease-related versus nondisease-related health utilisation}

Healthcare databases will vary widely in terms of the elements of health utilisation that are captured. Clinical trials of COPD, for example, may only capture healthcare use that is considered "disease-related", such as outpatient visits for bronchitis and inhaled medications. In contrast, administrative databases usually capture all healthcare use and it is often difficult to determine whether a particular item (e.g. an office visit) is related to the disease or not. As a result, the method for determining costs attributable to disease will vary with the database at hand. For those using restricted databases, researchers should address whether the databases truly capture all disease-related healthcare use. For those with general healthcare-use records, the issue is how to identify disease-attributable costs among all the captured resource items.

With restricted databases, if the researcher decides that all relevant healthcare use is captured, this should be stated and justified in the report. It is preferable to provide a list of items considered disease-related. If the researcher believes that all relevant healthcare use is not captured, then it is necessary to estimate relevant resource use from other sources. A complete discussion of estimation methods is beyond the scope of this article, but texts on the subject are available [38, 39].

When using general administrative databases, there are two options. One is to predefine items that are considered COPDrelated and identify those in the database. A second approach is to select a well-matched control group without the condition and take the difference in total utilisation and costs between cases and controls.

\section{Analysis issues}

Medical-care costs are characterised by certain distributional properties that must be accounted for in an analysis. Failure to account for these issues will result in biased estimates of cost and, possibly, misguided conclusions for the study.

First, costs accrue unevenly over time, and months or years can go by with "zeros" in the database. Second, costs are skewed with small numbers of patients having very high costs compared with other, larger numbers of patient groups across populations. Third, observations can be censored, that is, incomplete due to unenrolment or loss to follow-up. Fourth, retrospective studies are subject to uncontrolled factors that can confound the analysis.

Important recent advances in cost estimation can effectively address these issues. In rare cases where censoring is not an issue, two-part models with log transformation of dependent variables have traditionally been used to estimate costs in the setting of masses of observations with value equal to zero and skewed data $[40,41]$. More recently, generalised linear models have addressed the issue of skewness with a more flexible and probably more robust modelling format [42, 43]. Although almost universally present in economic databases, censoring has only recently been recognised as an issue that can bias cost studies [44, 45]. Methods have been developed to estimate costs in the face of censoring, including multivariate methods that can address potential confounding in retrospective analyses [45-47].

\section{Adjusting for comorbidity}

Individuals with COPD often have more comorbidity than age- and sex-matched persons without COPD because of the impact of smoking on developing coronary artery disease, cancers and other illnesses. In addition, persons with COPD may come from different socioeconomic groups than those without the disease, because smoking is disproportionate among those with lower socioeconomic standing and in certain racial and ethnic groups [48-50]. To estimate the impact of COPD on burden-of-illness or CEA studies, these factors must be controlled for.

Various methods used to control for comorbidity have been adapted to adjust for the impact of comorbid conditions on costs of care in multivariate analyses [51-54]. It is important that the method accounts both for the mix of conditions and the severity of each condition as they impact cost. Some studies have focused on diagnoses for hospitalisations [55], but more recent studies show that comorbidities found largely in the ambulatory setting can also be important [56]. Other studies have relied on pharmacy claims as measures of severity [57, 58], although such data are frequently unavailable from administrative or clinical trial databases.

\section{Outcomes}

Important issues related to identifying and valuing outcomes for COPD are reviewed elsewhere in this supplement. 
This article addresses important general issues for economic evaluations of COPD therapies. First, outcomes should incorporate both quality-of-life issues and time element, meaningful to patients, clinicians and insurers. The most widely accepted measure combining quality of life and survival time is the quality-adjusted life year (QALY) [5]. Since QALYs are well studied, stem from a solid theoretical foundation and allow decision-makers to compare healthcare interventions both within and across diseases, the authors recommend this measure for studies in COPD whenever feasible. Other measures of outcome, such as days without an exacerbation or days without oxygen, are also often meaningful to both patients and clinicians. These measures must be used with care, however, because some can influence both the numerator and denominator of a CEA (e.g. exacerbations). Such "double-counting" can severely influence the interpretability of these measures.

\section{Is there a need for a health-policy model?}

Given the complexity of the epidemiology, cost and consequences of treating COPD, a comprehensive disease and economic model may be a useful aid for decision-makers. Such models have been used to help project the future mortality, morbidity and cost of coronary heart disease, breast cancer and prostate cancer in the USA and Canadian populations [59-61]. The user of these models may simulate the effects of interventions, either preventive (i.e. smoking cessation) or therapeutic, upon mortality, morbidity and cost for an extended time horizon. Changing the inputs enables the user to evaluate the relative impact of alternative interventions on the incidence, prevalence and burden of COPD. The goal is to help policy-makers identify strategies that are the most cost-effective means of reducing the burden of this disease.

Several arguments favour developing such a model. This model could be designed for comparative evaluation of the many existing, new and "in-the-pipeline" treatments for COPD. Projected changes in the incidence and prevalence of COPD resulting from increases or decreases in smoking rates could be incorporated so that burden-of-illness calculations could be derived. Newer generation microsimulation models have been found to be quite robust and flexible [62-64], potentially allowing the user to gauge the impact of "micro" level inputs, such as changes in FEV1 on outcomes.

Designers need to take several steps for such models to be accepted and used by decision-makers. The model must follow the pathology of disease and accepted clinical pathways of treatment. It must be flexible enough to represent the diverse populations that can be affected by COPD. Risk factors that are important influences of the incidence and severity of COPD, such as age, sex and smoking history, should be included as cofactors in the model. The model's perspective must be that of the end-users; in some cases it is advantageous to be able to accommodate multiple perspectives. It must be transparent with all functions readily accessible for inspection and it should be applicable in a wide variety of settings. The end-points should be meaningful to caregivers and policy decision-makers and include clinical and economic end-points. Finally, and most importantly, the outcomes generated must be validated against observations from the "real world". To maximise the likelihood of addressing these issues, the authors recommend that the modelling process be iterative and involve as many stakeholders as possible during the development process.

In general, clinical decision-makers have been reluctant to make policy decisions on the basis of simulation models $[65,66]$. It can be argued, however, that such models offer a systematic approach to understanding the complex economic implications of alternative therapies for COPD, particularly when direct information from epidemiological studies or clinical trials is lacking. The alternative, such as "standard of care" or expert opinion, are much more difficult to define and validate.

\section{Conclusions}

The complex disease of chronic obstructive pulmonary disease has rapidly increased in incidence and prevalence in many countries throughout the world. Given the reality of limited healthcare budgets, economic evaluations can help place chronic obstructive pulmonary disease and its treatments in the context of interventions aimed at other conditions. Burden-of-illness studies, particularly those that focus on the productivity effects of chronic obstructive pulmonary disease, are needed for many developed and developing countries. Cost-effectiveness studies of new treatments are also important, as are comparisons of the benefits of primary, secondary and tertiary prevention for chronic obstructive pulmonary disease.

\section{References}

1. American Lung Association. Trends in chronic bronchitis and emphysema: morbidity and mortality. http://www.lungusa.org/ data/copd/COPD1.pdf. Chicago, American Lung Association, Epidemiology and Biostatistics Unit. March 2002. Accessed February 2003.

2. Staton GW Jr, Ingram RH Jr. Chronic obstructive diseases of the lung. In: Rubenstein E, Federman DD, eds. Scientific American Medicine. New York, WebMD Corp., 1995; pp. 1-25.

3. Murray CJ, Lopez AD. Evidence-based health policy lessons from the Global Burden of Disease Study. Science 1996; 274: 740-743.

4. Drummond MF, Jefferson TO. Guidelines for authors and peer reviewers of economic submissions to the BMJ. The BMJ Economic Evaluation Working Party. BMJ 1996; 313 : 275-283.

5. Siegel JE, Torrance GW, Russell LB, Luce BR, Weinstein MC, Gold MR. Guidelines for pharmacoeconomic studies. Recommendations from the panel on cost effectiveness in health and medicine. Panel on Cost Effectiveness in Health and Medicine. Pharmacoeconomics 1997; 11: 159-168.

6. Siegel JE, Weinstein MC, Russell LB, Gold MR. Recommendations for reporting cost-effectiveness analyses. Panel on Cost-Effectiveness in Health and Medicine. JAMA 1996; 276: 1339-1341.

7. Birch S, Gafni A. On being NICE in the UK: guidelines for technology appraisal for the NHS in England and Wales. Health Econ 2002; 11: 185-189.

8. Garber AM, Phelps CE. Economic foundations of costeffectiveness analysis. J Health Econ 1997; 16: 1-31.

9. Rice DP. Estimating the costs of illness. Am J Public Health 1967; 68: 424 440.

10. Rice DP. Estimating the Cost of Illness. Health Economics Series 6. Publication no. 947.6. Washington, US Government Printing Office, 1966.

11. Koopmanschap MA, van Ineveld BM. Towards a new approach for estimating indirect costs of disease. Soc Sci Med 1992; 34: 1005-1010.

12. Koopmanschap MA, Rutten FF. The impact of indirect costs on outcomes of health care programs. Health Econ 1994; 3: 385-393.

13. Koopmanschap MA, Rutten FF, van Ineveld BM, van Roijen L. The friction cost method for measuring indirect costs of disease. J Health Econ 1995; 14: 171-189.

14. Rothermich EA, Pathak DS. Productivity-cost controversies in cost-effectiveness analysis: review and research agenda. Clin Ther 1999; 21: 255-267. 
15. Hutubessy RC, van Tulder MW, Vondeling H, Bouter LM. Indirect costs of back pain in the Netherlands: a comparison of the human capital method with the friction cost method. Pain 1999; 80: 201-207.

16. Johannesson M, Karlsson G. The friction cost method: a comment. J Health Econ 1997; 16: 249-255.

17. Koopmanschap MA, Rutten FF. A practical guide for calculating indirect costs of disease. Pharmacoeconomics 1996; 10: 460-466.

18. Goeree R, O'Brien BJ, Blackhouse G, Agro K, Goering P. The valuation of productivity costs due to premature mortality: a comparison of the human-capital and frictioncost methods for schizophrenia. Can J Psychiatry 1999; 44: 455-463.

19. Ramsey SD, Sullivan SD, Kaplan RM, Wood DE, Chiang YP, Wagner JL. Economic analysis of lung volume reduction surgery as part of the National Emphysema Treatment Trial. NETT Research Group. Ann Thorac Surg 2001; 71: 995-1002.

20. Sullivan SD, Ramsey SD, Lee TA. The economic burden of COPD. Chest 2000; 117: Suppl. 2, 5S-9S.

21. Faulkner MA, Hilleman DE. The economic impact of chronic obstructive pulmonary disease. Expert Opin Pharmacother 2002; 3: 219-228.

22. Ruchlin HS, Dasbach EI. An economic overview of chronic obstructive pulmonary disease. Pharmacoeconomics 2001; 19 : 623-642.

23. Strassels SA, Smith DH, Sullivan SD, Mahajan PS. The costs of treating COPD in the United States. Chest 2001; 19: 344-352.

24. Ward MM, Javitz HS, Smith WM, Bakst A. Direct medical cost of chronic obstructive pulmonary disease in the U.S.A. Respir Med 2000; 94: 1123-1129.

25. Jacobson L, Hertzman P, Lofdahl CG, Skoogh BE, Lindgren B. The economic impact of asthma and chronic obstructive pulmonary disease (COPD) in Sweden in 1980 and 1991. Respir Med 2000; 94: 247-255.

26. Buck DJ, Richmond RL, Mendelsohn CP. Cost-effectiveness analysis of a family physician delivered smoking cessation program. Prev Med 2000; 31: 641-648.

27. Curry SJ, Grothaus LC, McAfee T, Pabiniak C. Use and cost effectiveness of smoking-cessation services under four insurance plans in a health maintenance organization. $N$ Engl J Med 1998; 339: 673-679.

28. Meenan RT, Stevens VJ, Hornbrook MC, et al. Costeffectiveness of a hospital-based smoking cessation intervention. Med Care 1998; 36: 670-678.

29. Fiscella K, Franks P. Cost-effectiveness of the transdermal nicotine patch as an adjunct to physicians' smoking cessation counseling. JAMA 1996; 275: 1247-1251.

30. Lennox AS, Osman LM, Reiter E, et al. Cost effectiveness of computer tailored and non-tailored smoking cessation letters in general practice: randomised controlled trial. BMJ 2001; 322: 1396.

31. Wasley MA, McNagny SE, Phillips VL, Ahluwalia JS. The cost-effectiveness of the nicotine transdermal patch for smoking cessation. Prev Med 1997; 26: 264-270.

32. Weiss SJ, Jurs S, Lesage JP, Iverson DC. A cost-benefit analysis of a smoking cessation program. Eval Program Plann 1984; 7: 337-346.

33. Molken MP, van Doorslaer EK, Rutten FF. Economic appraisal of asthma and COPD care: a literature review 1980-1991. Soc Sci Med 1992; 35: 161-175.

34. Pauwels RA, Buist AS, Calverley PM, Jenkins CR, Hurd SS, on behalf of the GOLD Scientific Committee. Global strategy for the diagnosis, management, and prevention of chronic obstructive pulmonary disease. NHLBI/WHO Global Initiative for Chronic Obstructive Lung Disease (GOLD) Workshop summary. Am J Respir Crit Care Med 2001; 163: 1256-1276.

35. Rennard SI. New therapeutic drugs in the management of chronic obstructive pulmonary disease. Curr Opin Pulm Med 2002; 8: 106-111.
36. Espino JU, Wagner MM. Accuracy of ICD-9-coded chief complaints and diagnoses for the detection of acute respiratory illness. Proc AMNIA Symp 2001; 1: 164-168.

37. Gold MR, Siegel JE, Russell LB, Weinstein MC. Time preference. In: Gold MR, Siegel JE, Russell LB, Weinstein MC, eds. Cost-Effectiveness in Health and Medicine. Oxford University Press, New York, 1996; pp. 214-235.

38. Gold MR, Siegel JE, Russell LB, Weinstein MC, eds. CostEffectiveness in Health and Medicine. Oxford University Press, New York, 1996.

39. Drummond MF, O'Brien BO, Stoddart GL, Torrance G. eds. Methods for the Economic Evaluation of Health Care Programmes. Oxford University Press, Oxford, 1997.

40. Manning WG. The logged dependent variable, heteroscedasticity, and the retransformation problem. $J$ Health Econ 1998; 17: 283-295.

41. Mullahy J. Much ado about two: reconsidering retransformation and the two-part model in health econometrics. J Health Econ 1998; 17: 247-281.

42. Manning WG, Mullahy J. Estimating log models: to transform or not to transform? J Health Econ 2001; 20: 461-494.

43. Blough DK, Ramsey SD. Using generalized linear models to assess medical care costs. Health Services Outcomes Res Methodol 2000; 1: 185-202.

44. Hallstrom AP, Sullivan SD. On estimating costs for economic evaluation in failure time studies. Med Care 1998; 36: 433-436.

45. Lin DY, Feuer EJ, Etzioni R, Wax Y. Estimating medical costs from incomplete follow-up data. Biometrics 1997; 53: 419-434.

46. Lin DY. Proportional means regression for censored medical costs. Biometrics 2000; 56: 775-778.

47. Etzioni Rd, Feuer EJ, Sullivan SD, Lin D, Hu C, Ramsey S. On the use of survival analysis techniques to estimate medical care costs. J Health Econ 1999; 18: 365-380.

48. Flint AJ, Yamada EG, Novotny TE. Black-white differences in cigarette smoking uptake: progression from adolescent experimentation to regular use. Prev Med 1998; 27: 358-364.

49. Healton $\mathrm{C}$, Messeri $\mathrm{P}$, Reynolds $\mathrm{J}$, et al. Tobacco use among middle and high school students - United States, 1999. Morb Mortal Wkly Rep 2000; 49: 49-53.

50. Faulkner DL, Escobedo LG, Zhu BP, Chrismon JH, Merritt RK. Race and the incidence of cigarette smoking among adolescents in the United States. $J$ Natl Cancer Inst 1996; 88: 1158-1160.

51. Fishman PA, Shay DK. Development and estimation of a pediatric chronic disease score using automated pharmacy data. Med Care 1999; 37: 874-883.

52. Deyo RA, Cherkin DC, Ciol MA. Adapting a clinical comorbidity index for use with ICD-9-CM administrative databases. J Clin Epidemiol 1992; 45: 613-619.

53. Naessens JM, Leibson CL, Krishan I, Ballard DJ. Contribution of a measure of disease complexity (COMPLEX) to prediction of outcome and charges among hospitalized patients. Mayo Clin Proc 1992; 67: 1140-1149.

54. McGuire TE. An evaluation of diagnosis-related group severity and complexity refinement. Health Care Financ Rev 1991; 12: 49-60.

55. Charlson ME, Pompei P, Ales KL, MacKenzie CR. A new method of classifying prognostic comorbidity in longitudinal studies: development and validation. J Chronic Dis 1987; 40: 373-383.

56. Klabunde CN, Potosky AL, Legler JM, Warren JL. Development of a comorbidity index using physician claims data. J Clin Epidemiol 2000; 53: 1258-1267.

57. Von Korff M, Wagner EH, Saunders K. A chronic disease score from automated pharmacy data. J Clin Epidemiol 1992; 45: 197-203.

58. Lamers LM. Pharmacy costs groups: a risk-adjuster for capitation payments based on the use of prescribed drugs. Med Care 1999; 37: 824-830.

59. Weinstein MC, Coxson PG, Williams LW, Pass TM, Stason WB, 
Goldman L. Forecasting coronary heart disease incidence, mortality, and cost: the Coronary Heart Disease Policy Model. Am J Public Health 1987; 77: 1417-1426.

60. Baker RD. Use of a mathematical model to evaluate breast cancer screening policy. Health Care Manag Sci 1998; 1: 103-113.

61. Grover SA, Coupal L, Zowall H, et al. The clinical burden of prostate cancer in Canada: forecasts from the Montreal Prostate Cancer Model. CMAJ 2000; 162: 977-983.

62. Habbema JD, van Oortmarssen GJ, Lubbe JT, van der Maas PJ. The MISCAN simulation program for the evaluation of screening for disease. Comput Methods Programs Biomed 1985; 20: 79-93.
63. Loeve F, Boer R, van Oortmarssen GJ, van Ballegooijen M, Habbema JD. The MISCAN-COLON simulation model for the evaluation of colorectal cancer screening. Comput Biomed Res 1999; 32: 13-33.

64. van der Maas PJ, de Koning HJ, van Ineveld BM, et al. The cost-effectiveness of breast cancer screening. Int $J$ Cancer 1989; 43: 1055-1060.

65. Weinstein MC, Toy EL, Sandberg EA, et al. Modeling for health care and other policy decisions: uses, roles, and validity. Value Health 2001; 4: 348-361.

66. Paltiel AD. Remarks on the role of economic modeling. Sex Transm Dis 2000; 27: 610-616. 